\title{
Coulisses
}

Revue de théâtre

25 | Hiver 2002

Varia

\section{Une structure renforcée, un bureau renouvelé}

\section{(2) OpenEdition}

1 Journals

Édition électronique

URL : http://journals.openedition.org/coulisses/6097

DOI : $10.4000 /$ coulisses. 6097

ISSN : 2546-9460

Éditeur

Presses universitaires de Franche-Comté

\section{Édition imprimée}

Date de publication : 1 janvier 2002

Pagination : 117-118

ISBN : 2-84627-052-X

ISSN : 1150-594X

\section{Référence électronique}

"Une structure renforcée, un bureau renouvelé », Coulisses [En ligne], 25 | Hiver 2002, mis en ligne le 24 octobre 2019, consulté le 15 novembre 2019. URL : http://journals.openedition.org/coulisses/6097 ; DOI : 10.4000/coulisses.6097

Ce document a été généré automatiquement le 15 novembre 2019.

Coulisses 


\section{Une structure renforcée, un bureau renouvelé}

\section{Des nouveaux...}

1 Le président : Bernard NORMAND.

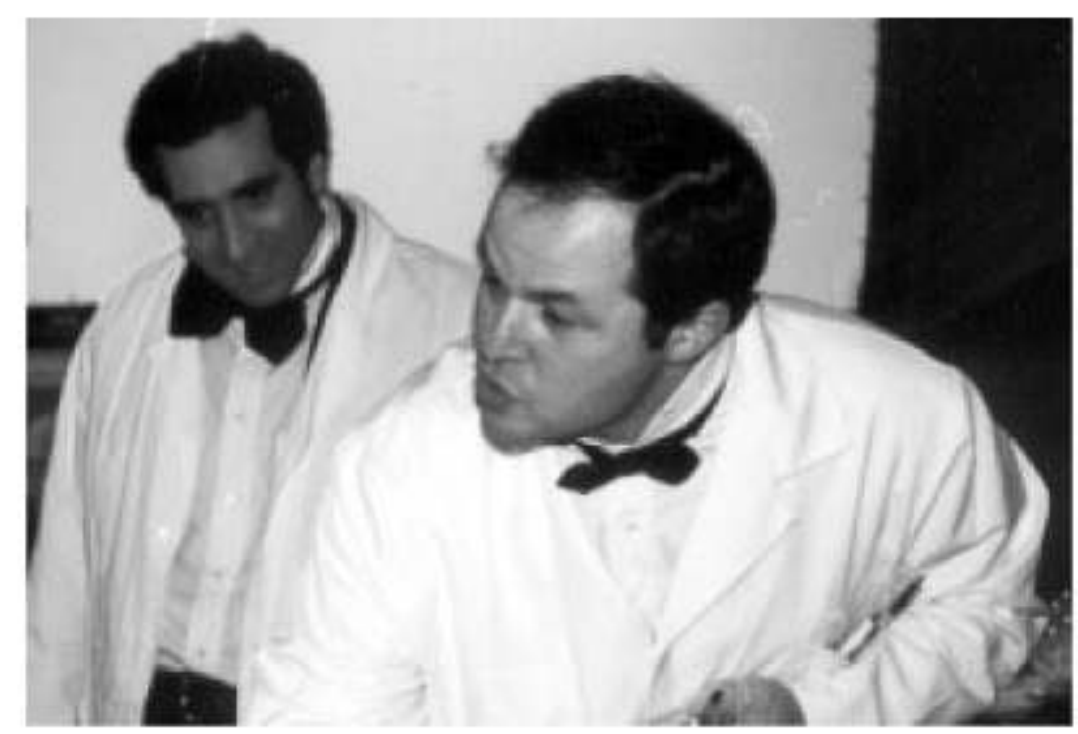

Photo G. Pannetton

2 Maître de conférence en chimie des matériaux, habilité à diriger des recherches, délégué auprès du CNRS pour l'année 2001-2002. Il remplace Lucile Garbagnati qui a œuvré pendant 16 ans à la vie et à la prospérité du TUFC. Il a joué au TUFC dès ses débuts, en 1987, avec Trajectoires (1988), Voix (1989), Electre (1990), Le Jardin des délices (1991), Il était une fois... (1994), L'Épidémie, d'Octave Mirbeau (1995).

3 La vice-présidente : Élodie GUIDOU, 


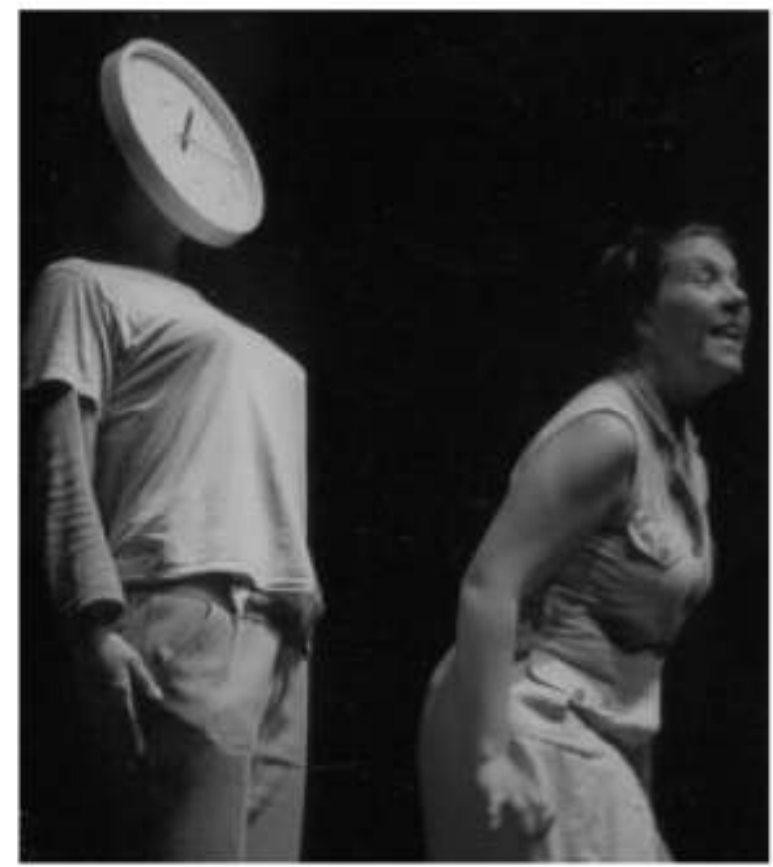

Photo G. Pannetton

4 étudiante en Licence de lettres modernes.

5 La secrétaire : Marie-Laure JUNGEN

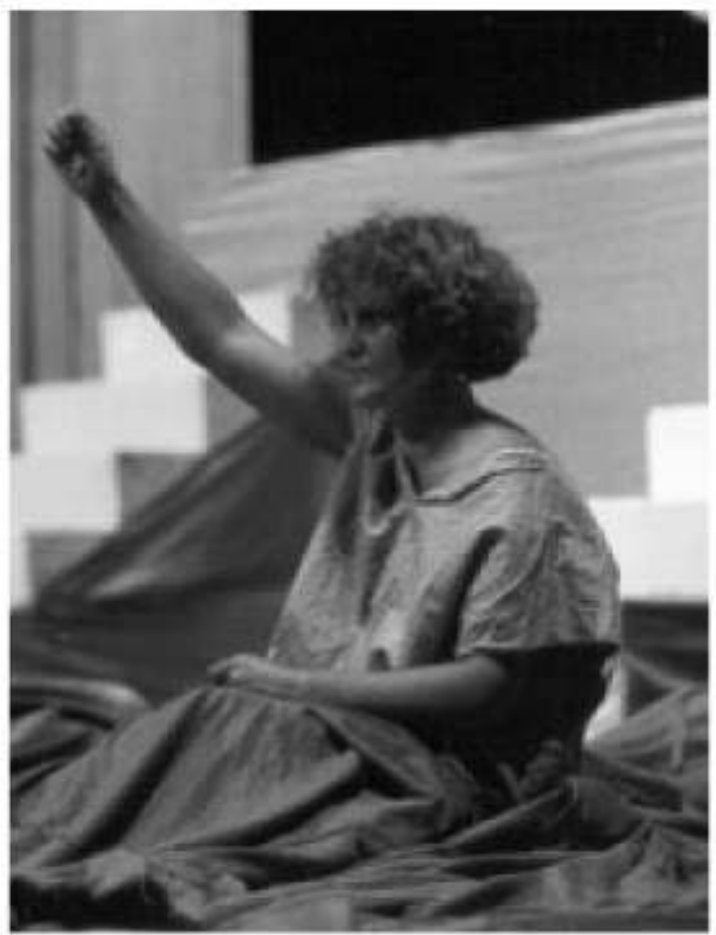

Photo G. Pannetton 
6 Secrétaire d'administration, de recherche et de formation à la bibliothèque des sciences de la Bouloie. Elle a joué dans Voix (1989), Le Jardin des délices (1991). Elle a suivi le parcours du TUFC depuis les débuts et s'y investit maintenant comme secrétaire de l'association.

7 La vice-secrétaire : Angélique RUCKLIN,

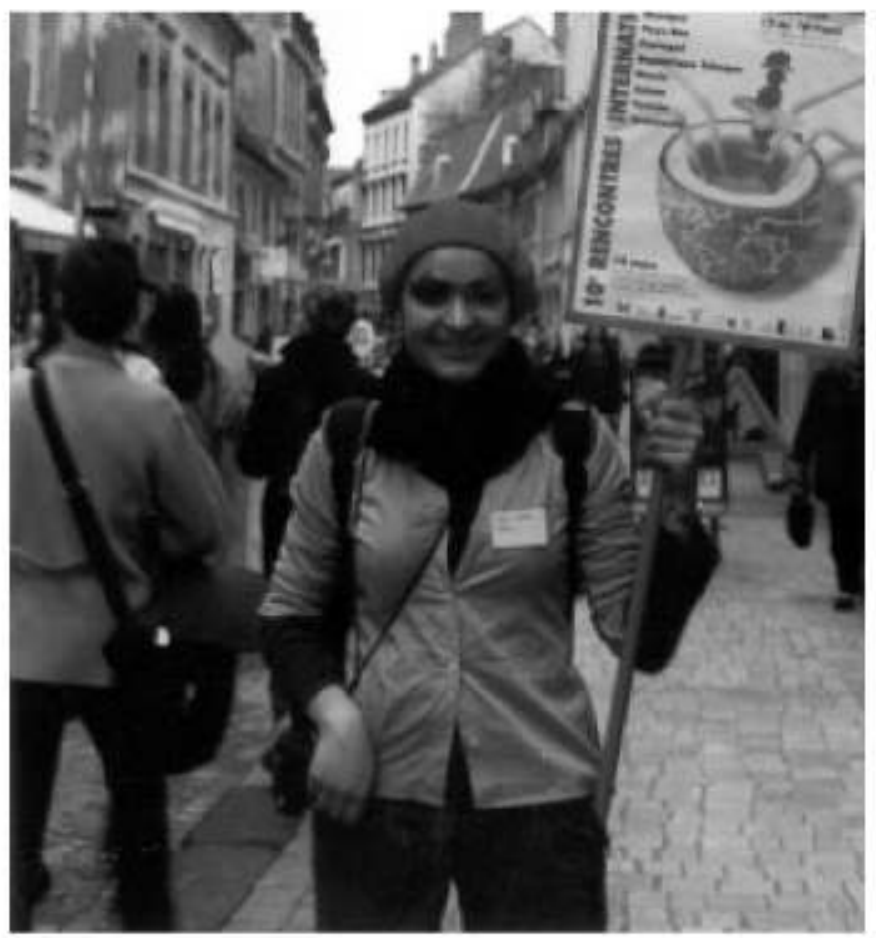

Photo G. Pannetton

8 étudiante en DEUG Théâtre $2^{\mathrm{e}}$ année. Elle a joué dans « R.A.S » (2001)

9 L'administratrice, en contrat emploi-Jeune : Ghislaine GAULTIER, 


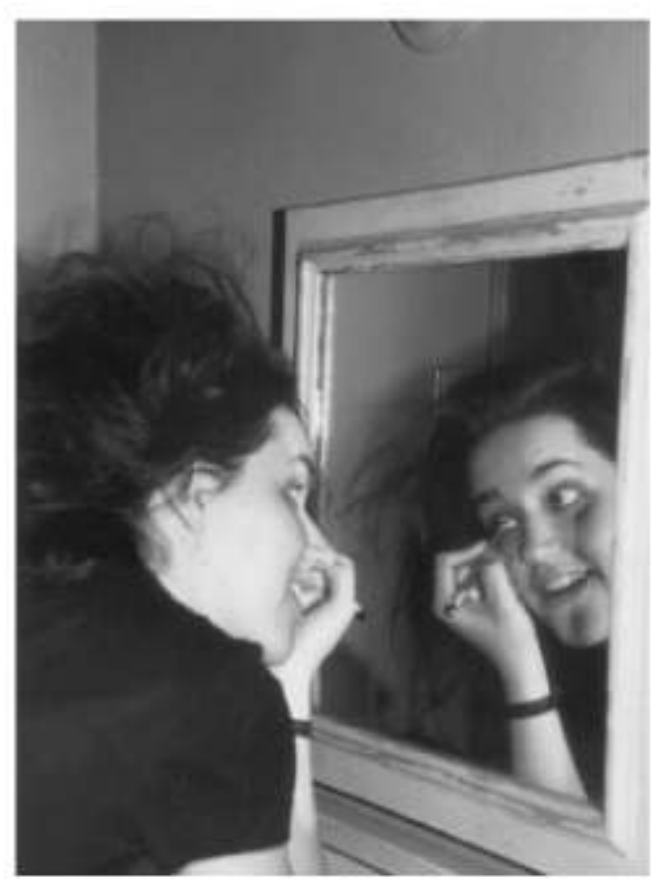

Photo G. Pannetton

10 a joué dans Guanikana, ou le Choc des Mondes en 1992-93, Corps en 1993-94. En 1994-95, en collaboration avec Régine Lamberti, elle a impulsé «Campus EnVie ». Il s'agissait d'animer les lieux universitaires francs-comtois, en partenariat avec les associations artistiques universitaires, et le concours de professionnels.

11 À MONTBÉLIARD, au campus des « Portes du Jura », Guy Barbier a laissé place à deux animatrices : Francine GAONACH et Mélanie MANUÉLIAN, étudiantes en Études théâtrales et membres du TUFC depuis 1998, elles ont toutes deux participé au spectacle Il est temps (2000). 


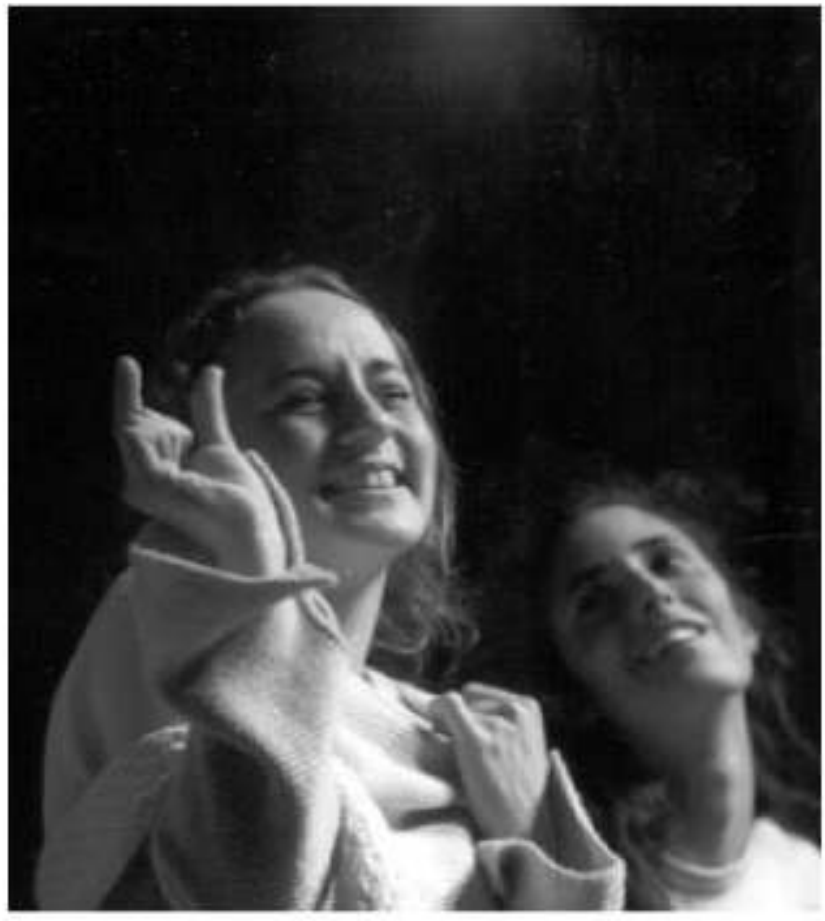

Photo G. Pannetton

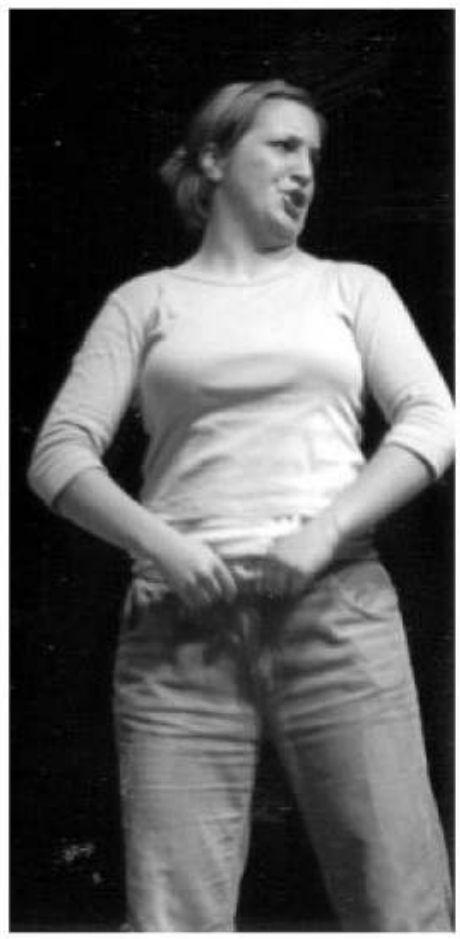

Photo G. Pannetton 


\section{Les piliers du TUFC...}

12 Joseph melcoRe, est le metteur en scène du T.U.F.C. Il dirige les trois ateliers de pratique théâtrale (expression, approfondissement, production) depuis 16 ans. Il est documentaliste au collège Sainte-Ursule à Besançon, et est chargé des cours d'art dramatique au Conservatoire national de région.

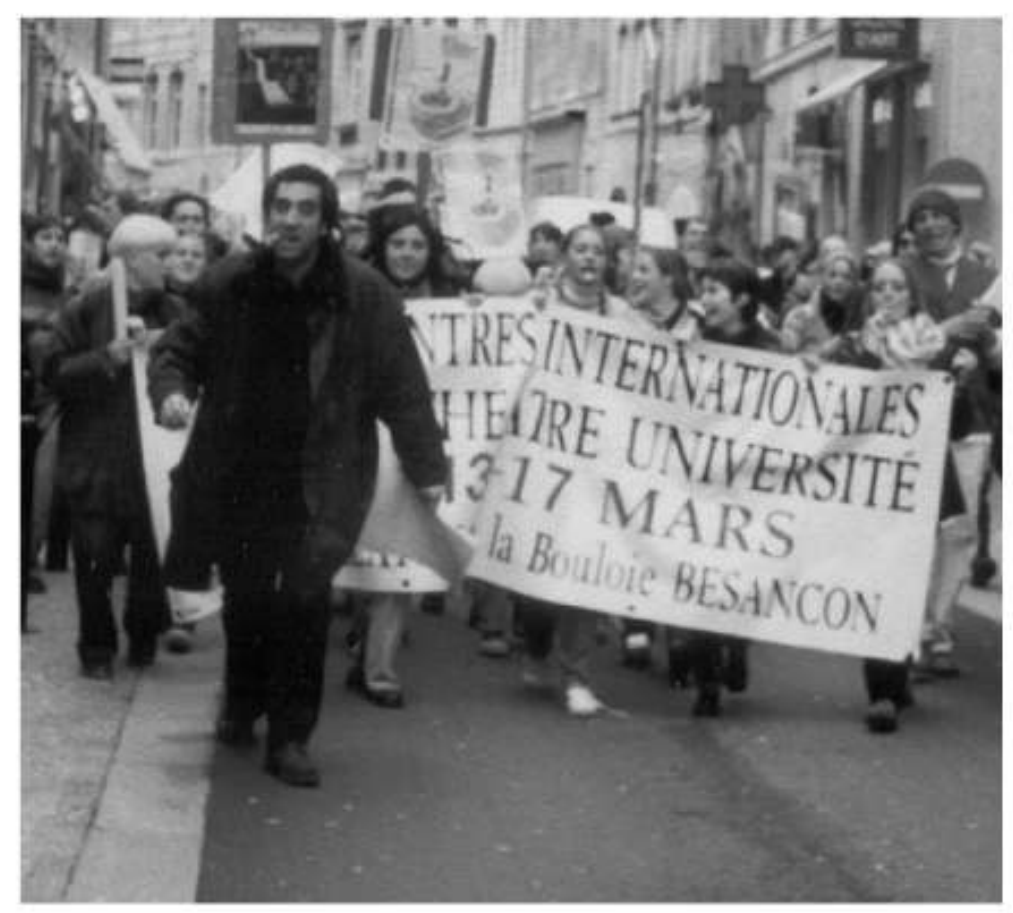

Photo G. Pannetton

13 La trésorerie est toujours assurée par Nicole CHABOUD. Secrétaire à l'agence comptable de la présidence de l'université de Franche-Comté. Elle a joué dans Actes (1987), Trajectoires (1988), Voix (1989) et Électre (1990).

14 À MONTBÉLIARD, Laurence ANDERHUEBER et Françoise CHAMBEFORT continuent à veiller sur les bonnes destinées du TUFC.

15 Lucile GARBAGNATI continue à assurer la direction de Coulisses et à animer, en collaboration avec Bernard Normand, l'atelier «Médiation culturelle", qui a pour objet l'organisation des Rencontres internationales du Théâtre universitaire, et de la Résidence-Création d'Armand Gatti, en été 2002. 